\title{
Samuel S. Franklin: The Psychology of Happiness; a Good Human Life
}

\author{
Cambridge University Press, Cambridge, 2010, 179 pp, \\ ISBN 978-0-521-13867-3
}

\author{
Ad Bergsma
}

Published online: 20 March 2010

(C) The Author(s) 2010. This article is published with open access at Springerlink.com

Writing a review is supposed to be an exercise in good judgment, but I have never been able to apply the idea of the golden mean to an activity like this. Aristotle placed it in the center of his philosophy. Aristotle asks the following from us: 'The mean and the good is feeling [or acting] at the right time, about the right things in relation to the right people and for the right reason'. For a reviewer it would probably mean to be critical of major flaws, appreciative of the most important strengths, in accordance with the importance of the author in the intellectual landscape of the moment, and not to let personal preferences interfere with the process.

This is a task I never will be up to, and the same is probably true for most people, trying to live a good and happy life according to Aristotle's principles. This has not prevented Samuel Franklin, Professor Emeritus of Psychology at California State University, to take the quote from Aristotle mentioned above and to place it in the center of his book about the psychology of happiness. He repeats it several times.

Franklin invites the reader to reflect on a rich history of ideas in Greek philosophy and modern psychology about the good life. This approach can give a sense of direction, but it has the obvious shortcoming that it is difficult to connect such abstract ideas with specific choices people have to make. I felt some frustration about the high level of abstraction that is characteristic of Franklins writing throughout the book.

Franklin uses Aristotle's theory as a base, in which he incorporates newer ideas from psychology. He takes Aristotle's concept of 'eudaimonia', that is virtuous activity with the positive feelings that usually accompanying it, as a starting point for thinking about happiness and adds the newer ideas of self-realization. For Franklin happiness is a synonym for fulfilling one's potential, just like it is the destiny of an acorn to become an oak. The late Dutch psychologist Duijker (Duijker 1979) has criticized this approach with the suggestion that some people may be gifted with the talent to play three dimensional pool, which could be played in spaceships that are outside the reach of gravity. The gifted

A. Bergsma $(\square)$

Erasmus University Rotterdam, Rotterdam, The Netherlands

e-mail: bergsma@fsw.eur.nl; a.bergsma@vumc.nl1 
humans living at this moment are unable to fulfill this potential and cannot flourish, because life on Earth does not offer the possibility of 3D pool yet. This may be an artificial and somewhat silly example, but it shows that the ideology of self-actualizing is appealing at face value, but gets complicated if you start to think about it thoroughly.

This problem occurs for example as Franklin explains the difference between real goods and apparent goods. The real goods are necessities to grow, and the apparent goods are pleasurable, but will not make you happy (that is, will not help you to grow). Franklin explains op page 54: 'A new car, a piece of jewelry, an expensive dress may be desirable, but they don't fulfill any human need. You may need a car to get to work and perform the tasks of everyday living, but no one needs a new Hummer'. In this passage it is easy to get the drift, and it may be a valuable thought that helps people to keep their lives on track, but it certainly does not enable me to make a clear distinction between the real and apparent goods in my own life.

My negative feelings about such practical shortcomings are more than compensated by positive feelings. Franklin offers a brief overview of the idea that happiness is a synonym with virtuous self-actualization and puts important psychological concepts in this context, such as intrinsic motivation, moral development, Maslow's need hierarchy, and emotion theory. Franklin offers a balanced treatment of the subject. He does not pretend to offer groundbreaking views, he is modest about the importance of modern science and calls attention to some of the best ideas in psychology. His major strength is that he treats the work of psychologists such as James, Csikszentmihalyi, Maslow and Seligman not in isolation, but places their contributions in the history of ideas that started with Aristotle.

Franklin treats psychology about the good life as footnotes to Aristotle, and one could argue that the book is not about the psychology of happiness. Instead he allows empirical psychology to slip back in the realm of philosophy. Franklin is not interested in the nittygritty details of data or in providing proof to choose one position over the other, but instead uses Aristotelian philosophy and modern psychology as means to construct a coherent world view. He is not interested in the falsification of ideas, but he is selectively interested in theories and ideas that support Aristotle.

A small anecdote gives an impression of his approach. He discusses Maslow's idea that self-actualizing people 'stand relatively detached from the fray' and tend to enjoy solitude and privacy. This makes Franklin think of Einstein who had a 'dismal performance as a husband and a father', but also had 'a passionate sense for social justice'. For Franklin this interesting contradiction is simply 'an admirable quality taken to the extreme'. He does not suggest that the lack of social ties could also be explained as indicating that Einstein did not fulfill his potential for loving and kindness. It takes a friendly outlook to offer such a positive explanation.

Franklin is just as friendly about the theories and ideas he considers worthwhile. In this way he reaches his own synthesis of Aristotle's philosophy and scientific psychology. This means that this book is suited for at least two audiences. It is an excellent introduction to Aristotle's philosophy and the ideas in psychology, which are relevant for thinking about the good life. Above that it is interesting for people who look for a synthesis in the burgeoning field of happiness research, and who do not like the hedonistic variants of happiness. I found it a pleasure to accompany Franklin on his search for meaning in happiness research, but at times I wished he had been more critical, and would have paid more attention to the drawbacks and the alternatives. Franklin did an excellent job, but still the golden mean for Franklin and me seem to be different. 
Open Access This article is distributed under the terms of the Creative Commons Attribution Noncommercial License which permits any noncommercial use, distribution, and reproduction in any medium, provided the original author(s) and source are credited.

\section{Reference}

Duijker, H. C. J. (1979). De problematische psychologie. Boom: Meppel. 